TEGAR 4 (1) (2020) 45-48
Journal of Teaching Physical Education in Elementary School
Available online at :
https://ejournal.upi.edu/index.php/tegar/article/view/28569
DOI: https://doi.org/10.17509/tegar.v4i1.28569

\title{
The Impact of Physical Education Learning on Healthy Life Style Knowledge of Elementary School
} Students

Gita Febria Friskawati, Agus Santosa, Reza Sanjaya

STKIP Pasundan Cimahi, Indonesia

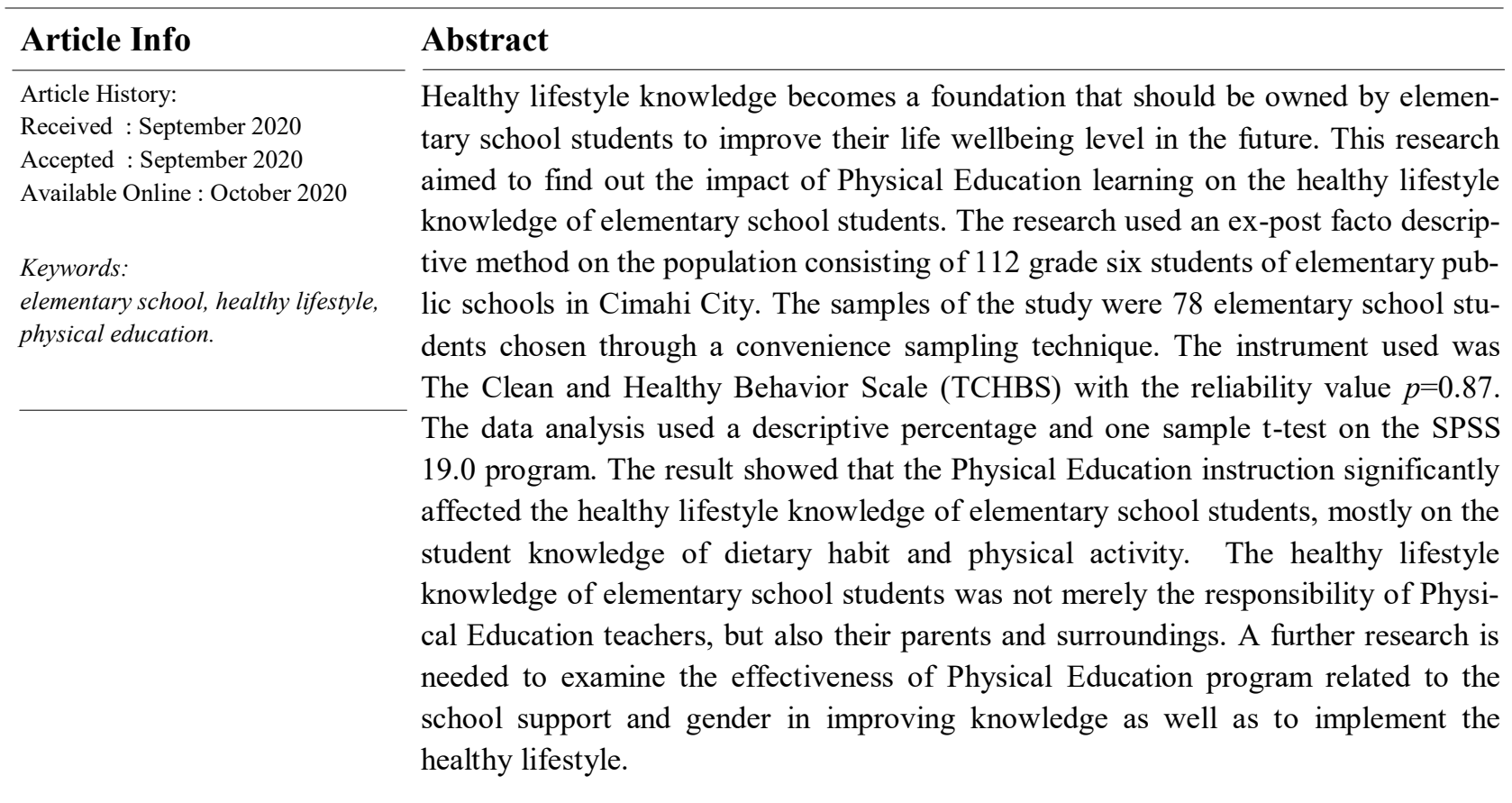




\section{INTRODUCTION}

Health is the main factor that is important for the sustainability of life, especially in the childhood age when the children grow and develop. The foundation of healthy life is laid on the childhood age where the balance dietary habit and active movement will provide the important nutrition for a healthy growth and development. On the other hand, nutrition intake and passive movement will result in obesity in the childhood period that eventually arouses chronical diseases in the adolescent and adulthood periods as well as a poor academic behavior and performance (Perera \& Frei, 2015).

The definition of health, according to the World Health Organization (WHO), is not only a condition of the absence of diseases and weaknesses, but also the presence of the balance function of physical, mental, and social aspects. Therefore, the life quality measurement related to health covers three functions, including physical aspects, psychological aspects (cognitive and emotional aspects), and social aspects (Vionalita, 2017). Meanwhile, healthy lifestyle promoting health includes activities which focus on the improvement of a person life wellbeing level. The activities focus on the positive physical, social, mental, intellectual, and spiritual health potential developments (Sopa, 2018). Therefore, a healthy lifestyle should be implemented in the young age.

The immobility and the lack of healthy behaviors are the main reasons of health problems nowadays. Healthy lifestyle behaviors could decrease the diseases and mortality. The scale of healthy lifestyle developed in this context includes physical activity, self-fulfillment, health responsibility, nutrition, support among people, and stress management component. The improvement of healthy lifestyle knowledge of the students is the responsibility of Physical Education teachers (Bozlar \& Arslanoğlu, 2016).

The promotion of healthy lifestyle has gained its popularity as the tool to develop the children health. The study shows that healthy lifestyle could improve physical, psychological, and social health for a lifetime and improve the quality of life, as well as decrease the morbidity and mortality (Pomohaci, 2018). Physical Education at school is one of subjects promoting healthy lifestyle for students. Physi- cal Education refers to a learning process in form of an aimed physical activity, through an organized participation, self-expression, physical fitness improvement, and healthy lifestyle for life wellbeing to maintain a civilized social relationship, and is directed to the competitive attainment in all levels (Ana-maria, 2015).

Physical Education has a central role to develop a healthy life style of students. Physical Education teaches students to manage daily eating habit and movement habit (Brubaker, 2018). By using physical activities, Physical Education could improve the student's wellbeing, a good life quality, and healthy lifestyle knowledge by avoiding diseases and premature death. Recently, a result of a study shows that Physical Education through physical activities could be a treatment for mental health problems (Al-nakeeb, Lyons, Dodd, \& Al-nuaim, 2015).

Previous research regarding the position of Physical Education in promoting health shows a high negative health behaviors of the students, especially sedentary behavior and the low physical activity level (Kostecka, Bojanowska, \& Stoma, 2018). Another research studied physical activity as a factor improving health found that the level of physical activity decreased drastically in the transition period from elementary school level to middle school until higher school levels (WHO, 2019). The level of healthy lifestyle should be built in the elementary school age as the future foundation $(\mathrm{Gu}$, Chang, \& Solmon, 2016). Although Physical Education instruction promotes healthy lifestyle to the students, the students are still lack of knowledge about healthy lifestyle in their environments (Turkmen \& Kul, 2013). The aim of this research was to find out the healthy lifestyle knowledge of elementary school students, especially upper-class students who will face the transition period from the elementary school level to the middle school level.

\section{METHOD}

The research method used to find out the impact of Physical Education learning on the elementary school student knowledge regarding healthy lifestyle was a descriptive ex-post-facto method. The populations of the study were 112 sixth grade elementary school students of public schools in Cimahi City. The grade six students were chosen as they are in the transition period from the elementary level to 
the middle school level, where they were vulnerable to movement behavior and lifestyle changes, especially a significant healthy life (Gu, et al., 2016). The populations were taken from six public elementary schools in Cimahi City. The samples of the study were 78 elementary school students chosen through the convenience sampling technique as the samples were chosen from the nearest schools (Etikan, Musa, \& Alkassim, 2017).

The data collection was administered by using a Clean and Healthy Behavior Scale (TCHBS) questionnaire from (Vionalita, 2017) with a Likert scale. The questionnaire had been tested for its validity and reliability. The reliability value was $p=0.87$, which means that the questionnaire was reliable to be used. Data obtained from the questionnaire were analyzed by using a descriptive statistical analysis with percentage calculation to find out the impact of Physical Education instruction on the level of student active lifestyle knowledge.

\section{RESULT \& DISCUSSION}

The results of the obtained data depicted the percentage of each sub variable of The Clean and Healthy Behavior Scale (TCHBS), including (1) Clean Behavior, (2) Eating and Drinking Habits, (3) Rest Pattern, (4) Physical Activity Pattern, and (5) Personal Health Knowledge. Table 1. explains the results of percentage calculation of each variable from the questionnaire.

Table 1. Percentage Results of The Clean and Healthy Behavior Scale (TCHBS)

\begin{tabular}{lll}
\hline \multicolumn{1}{c}{ Sub Variabel } & Frequency & $\%$ \\
\hline Healthy life & 44 & 36 \\
\hline Eating and drinking habits & 65 & 54 \\
\hline Rest pattern & 32 & 26 \\
\hline Physical activity pattern & 56 & 46 \\
\hline Personal health knowledge & 45 & 37 \\
\hline
\end{tabular}

Data in table I. show the student knowledge of healthy lifestyle. The eating and drinking habits gained the highest percentage (54\%). Most of elementary school students, aged 10-12 year old or equal to grade six, have a high appetite (Perera \& Frei, 2015). Therefore, it is easy for the teachers to promote eating and drinking habits to the children in this age. Elementary school teachers have a strong motivation to teach nutrition and dietary habit to the students as they perceive that the growth and development at this age is important (Al-nakeeb et al., 2015). Physical Education instruction also focuses on the tips to improve healthy nutrition for the students and to motivate the students to consume a balance nutrition, thus the Physical Education teachers are prompted to spend efforts to improve the physical, mental, and self-efficacy conditions to help the students improve their quality of life (Ana-maria, 2015).

The student's knowledge about physical activity was $46 \%$. The participation of elementary school students in sporting activities is aimed to fulfill their movement needs as school is the most feasible place to meet their movement needs. The school age children in Indonesia mostly spend their time at school. The priority goal of Physical Education at school is as a preventive act to help students improve their physical activity in order to gain a dynamic health (Setyorini, 2017). Some researchers had studied the relationship between physical activity opportunity time in Physical Education instruction and the student fitness, especially at the elementary school level, that showed the presence of a significant relationship (Cheung, et al., 2019). Generally, the Physical Education program at elementary schools could affect the student's healthy life knowledge to prevent and to cure obesity. 12-14\% students have obesity, which is different in different regions. A recent study on the elementary school graduates found that $9,7 \%$ male children aged 13 years and 3,9\% female children aged 13 years are overweight. The presence of Physical Education program promoting healthy lifestyle could decrease it into $32 \%$ (Kostecka et al., 2018).

A balance diet and physical activity behaviors give impacts on the health improvement and facilitate a healthy weight management. Besides, parents and environments can be influential factors of the student healthy lifestyle knowledge level (Bozlar \& Arslanoğlu, 2016). The parent awareness improvement contributes to the decrease of their children weight. The change of lifestyle, including a higher physical activity level in the family, could motivate children to do sporting activities and to participate in sports as the main key (Cloes, 2017). 


\section{CONCLUSION}

The highest result of Physical Education instruction was on the student knowledge of dietary habit and physical activity. The healthy life behavior knowledge is not merely affected by the Physical Education program, but also affected by parents who also promote the healthy lifestyle. In addition, gender can be an influential factor. Further research, in relation to the school support and gender, is needed to find out the effectivity of Physical Education in improving knowledge as well as implementing the student healthy lifestyle.

\section{REFERENCE}

Al-Nakeeb, Y., Lyons, M., Dodd, L. J., \& AlNuaim, A. (2015). An Investigation into The Lifestyle, Health Habits and Risk Factors of Young Adults. International journal of environmental research and public health, 12(4), 4380-4394. https://doi.org/10.3390/ ijerph12040438.

Ana-maria, V. (2015). Study on Promoting Quality of Life through Physical Exercise. Procedia Social and Behavioral Sciences, 180 (November 2014), 1439-1443. https:// doi.org/10.1016/j.sbspro.2015.02.290

Bozlar, V., \& Arslanoglu, C. (2016). Healthy Life Style Behaviors of University Students of School of Physical Education and Sports in Terms of Body Mass Index and Other Variables. Universal Journal of Educational Research, 4(5), 1189-1195. https:// doi.org/10.13189/ujer.2016.040532.

Brubaker Jr, K. D. (2011). The Importance of Physical Education in Today's Schools (Doctoral dissertation, Ashland University).

Cloes, M. (2017). Preparing Physically Educated Citizens in Physical Education: Expectations and Practices. Retos: nuevas tendencias en educación física, deporte y recreación, (31), 245-251.

Etikan, I., Musa, S. A., \& Alkassim, R. S. (2016). Comparison of Convenience Sampling and Purposive Sampling. American journal of theoretical and applied statistics, 5(1), 1-4. https:// doi.org/10.11648/j.ajtas.20160501.11

Gu, X., Chang, M., \& Solmon, M. A. (2016). Physical activity, Physical Fitness, and HealthRelated Quality of Life in School-Aged Children. Journal of Teaching in Physical Education, 35(2), 117-126. https://doi.org/10.1123/ jtpe.2015-0110.
Cheung, P. C., Franks, P. A., Kramer, M. R., Kay, C. M., Drews-Botsch, C. D., Welsh, J. A., \& Gazmararian, J. A. (2019). Elementary School Physical Activity Opportunities and Physical Fitness of Students: A Statewide Crosssectional Study of Schools. PloS one, 14(1), e0210444.

Kostecka, M., Bojanowska, M., \& Stoma, M. (2017). The Role of Physical Activity in Instilling Healthy Lifestyle Habits in Children. Baltic Journal of Health and Physical Activity. The Journal of Gdansk University of Physical Education and Sport, 9(3). https:// doi.org/10.29359/BJHPA.09.3.13.

Perera, T., Frei, S., Frei, B., Wong, S. S., \& Bobe, G. (2015). Improving Nutrition Education in US Elementary Schools: Challenges and Opportunities. Journal of Education and Practice, 6(30), 41-50.

Sopa, I. S., \& Pomohaci, M. (2018). Developing a Healthy Lifestyle of Students Through the Practice of Sport Activities. Land Forces Academy Review, 23(3), 207-218. https:// doi.org/10.2478/raft-2018-0025.

Setyorini, S., \& Indahwati, N. (2017). First Grade Primary School Students' Physical Activity Level on Physical Education Subject through Live Life Well at School Program. Materials Science and Engineering, 180(12178), 1-6. https://doi.org/10.1088/1742$6596 / 755 / 1 / 011001$

Turkmen, M., Kul, M., Ocalan, M., Ozkan, A., \& Bozkus, T. (2013). Determination of The Relationship between Physical Activity Levels and Healthy Lifestyle Behaviors of University Students. Australian Journal of Basic and Applied Sciences, 7(10), 507-512.

Vionalita, G., \& Kusumaningtiar, D. (2017, October). Knowledge of Clean and Healthy Behavior and Quality of Life among SchoolChildren. In Health Science International Conference (HSIC 2017). Atlantis Press. https:// doi.org/10.2991/hsic-17.2017.67.

World Health Organization. (2019). Guidelines on Physical Activity, Sedentary Behaviour and Sleep for Children Under 5 Years of Age: web annex: evidence profiles (No. WHO/NMH/ PND/19.2). World Health Organization. 